\title{
UPAYA PENINGKATAN KESEJAHTERAAN MASYARAKAT MELALUI PROGRAM KUBE PKH DI KABUPATEN CIAMIS
}

\section{EFFORTS TO IMPROVE COMMUNITY WELFARE THROUGH THE PKH KUBE PROGRAM IN THE DISTRICT CIAMIS}

\author{
Tiktiek Kurniawati*, Rian Kurnia \\ Program Studi Agribisnis Fakultas Pertanian Universitas Galuh \\ *Email: tiktiekkurniawati@gmail.com \\ Diterima 12-11-2020; Disetujui 29-12-2020)
}

\begin{abstract}
ABSTRAK
KUBE-PKH adalah salah satu program yang dilakukan pemerintah dalam penanganan kemiskinan melalui kelompok usaha berupa kelompok warga atau keluarga binaan sosial yang dibentuk oleh warga atau keluarga binaan sosial yang telah dibina melalui proses kegiatan Program Kesejahteraan Sosial (PROKESOS) sebagai sarana untuk meningkatkan taraf kesejahteraan sosialnya. Penelitian dilakukan dengan menggunakan metode survey. Hasil penelitian menunjukkan bahwa (1) Dari ketiga kecamatan diantaranya Kecamatan Sukamantri, Kecamatan Panjalu dan Kecamatan Rajadesa semuanya menunjukkan hasil bahwa program KUBE yang telah dilaksanakan rata-rata telah memenuhi ukuran upaya peningkatan kesejahteraan masyarakat, dan (2) Kendala-kendala dalam pelaksanaan KUBE-PKH ini diantaranya adalah sumberdaya manusia, pendidikan dan ekonomi.
\end{abstract}

Kata Kunci: Peningkatan, Kesejahteraan Masyarajat, KUBE

ABSTRACT

KUBE-PKH is one of the programs carried out by the government in handling poverty through business groups in the form of community groups or social assisted families formed by members or social assisted families who have been fostered through the process of Social Welfare Program (PROKESOS) activities as a means of increasing the social welfare. The method in this research is to use survey research methods. Survey research is research that takes a sample from one population as a basic data collection tools. The result is that 1. Of the three Districts including Sukamantri District, Panjalu District and Rajadesa District, all of them show the results that the $K U B E$ program that has been implemented on average has met the measure of efforts to increase community welfare. 2. The obstacles in implementing KUBE-PKH include human resources, education and economy.

Keywords: Improvement, Community Welfare, KUBE

\section{PENDAHULUAN}

Dalam kebijakan sosial,

kesejahteraan sosial menunjuk ke jangkauan pelayanan untuk memenuhi kebutuhan masyarakat. Indikator kesejahteraan adalah kecilnya persentasi kemiskinan suatu daerah. Sebagai upaya percepatan penanggulangan kemiskinan, sejak tahun 2007 pemerintah Indonesia telah melaksanakan Program Bantuan Tunai Bersyarat (BTB) yang dikenal dengan nama Program Keluarga Harapan (PKH) sebagai salah satu tahapan menuju sistem perlindungan sosial. Sistem baru 
penyaluran bantuan sosial ini diatur dengan Peraturan Presiden Nomor 63 Tahun 2017 tentang Penyaluran Bantuan Sosial Secara Non Tunai. PKH akan memberikan manfaat jangka pendek dan jangka panjang. Banyak hal yang dilakukan dalam menangani kesejahteraan, baik itu dari pemerintah, swasta maupun kesadaran dari masyarakat. Salah satu program yang dilakukan pemerintah dalam penanganan kemiskinan adalah melalui Kelompok Usaha Bersama (KUBE). Kelompok warga atau keluarga binaan sosial yang dibentuk oleh warga atau keluarga binaan sosial yang telah dibina melalui proses kegiatan Program Kesejahteraan Sosial (PROKESOS) sebagai sarana untuk meningkatkan taraf kesejahteraan sosialnya.

Secara administratif Kabupaten Ciamis terdiri atas 27 kecamatan, 7 kelurahan, 258 desa, 1.224 dusun, 2.913 RW dan 9.143 RT. Kabupaten Ciamis merupakan salah satu kabupaten di Provinsi Jawa Barat, letaknya berada diujung tenggara Provinsi Jawa Barat. Menurut data diperoleh keterangan bahwa pada tahun 2018 Dinas Sosial (Dinsos) Kabupaten Ciamis menyalurkan Rp 940 juta untuk 47 Kelompok Usaha Bersama Program Keluarga Harapan
(Kube-PKH). Kegiatan ini sebagai upaya meningkatkan perekonomian warga miskin, karena mereka diberikan modal untuk berusaha bersama untuk menjadi mandiri dalam mendapatkan penghasilan tetap sehingga dapat mendorong masyarakat menuju masyarakat sejahtera.

Keberadaan Kelompok Usaha Bersama (KUBE) di tengah-tengah masyarakat Kabupaten Ciamis diharapkan dapat menjadi sarana dalam meningkatkan Usaha Ekonomi Produktif (UEP), khususnya dalam peningkatan pendapatan. Kehadiran KUBE merupakan media untuk meningkatkan motivasi warga untuk lebih maju secara ekonomi dan sosial. Dalam menjalankan usahanya, KUBE PKH bisa menjalin kerja sama dengan Badan Usaha Milik Desa (BUMDes) atau pun perbankan untuk menyelesaikan masalah permodalan, sehingga usaha yang dijalankan dapat lebih maju. Namun demikian, kenyataan di lapangan tidak selalu berjalan dengan yang diharapkan. Masih banyak kekurangan yang harus dibenahi khususnya terkait dengan proses/teknis pelaksanaannya agar program ini dapat sampai kepada orang yang tepat sehingga dapat dirasakan manfaatnya bagi masyarakat. Adanya beberapa fakta di lapangan yang salah 
satu faktor yang harus ditekankan pada program KUBE adalah faktor kemandirian, dalam arti setelah diberikan bantuan, penerima program KUBE ini diharapkan dapat memiliki suatu usaha sehingga dapat menambah penghasilan bagi diri dan keluarganya dalam rangka meningkatkan kesejahteraan keluarganya. KUBE merupakan metode pendekatan yang terintegrasi dan keseluruhan proses program kesejahteraan sosial.

\section{METODE PENELITIAN}

Penelitian ini merupakan penelitian evaluasi yang dilaksanakan dengan mengunakan penelitian survey. Menurut Singarimbun (1989), penelitian survai adalah penelitian yang mengambil sampel dari satu populasi sebagai alat pengumpulan data yang pokok.

Data yang digunakan dalam penelitian ini terdiri atas data primer dan data sekunder. Data primer (ketepatan sasaran, sosialisasi program, tujuan program, dan pemantauan program) diperoleh melalui wawancara dengan menggunakan kuesioner yang telah dipersiapkan sebelumnya. Sedangkan data sekunder diperoleh melalui penelusuran referensi maupun data publikasi dari dinas atau instansi terkait. Analisis data dilakukan dengan menggunakan analisis deskriptif kualitatif.

\section{HASIL DAN PEMBAHASAN}

Kondisi Umum Kelompok Pelaksana KUBE PKH

\section{KUBE PKH di Kecamatan Sukamantri}

Tahun 2007 merupakan tahun dimana untuk pertama kalinya Indonesia melalui Kementerian Sosial menyelenggarakan $\mathrm{PKH}$ (Program Keluarga Harapan) dengan cita-cita atau harapan bahwa keluarga pra-sejahtera dapat menuju sejahtera terutama dalam bidang ekonomi dan pendidikannya. Dengan sejahteranya ekonomi dan pendidikan maka akan terselenggaranya sumber daya manusia yang berkualitas.

Berawal dari tujuan Program Keluarga Harapan (PKH) yaitu untuk mengurangi angka kemiskinan, selanjutnya untuk meningkatkan kualitas sumber daya manusia (pendidikan), serta mengubah perilaku yang kurang mendukung peningkatan kesejahteraan dari kelompok paling miskin, maka langkah pemerintah daerah selanjutnya yaitu membentuk program keberadaan Kelompok Usaha Bersama (KUBE-PKH) dimana anggota dari kelompok ini yaitu 
para keluarga PKH (Program Keluarga Harapan).

KUBE merupakan organisasi pengusaha kecil yang memiliki tujuan yang sama. KUBE memiliki pendamping dari petugas kecamatan yaitu bapak Desi Setiadi, Ibu Nurlinda, Bapak Aceng Durrahman dan Ibu Nanda. Sekitar tahun 2016 Kelompok Usaha Bersama (KUBE) dibentuk dan memiliki ketua, sekretaris, bendahara dan anggota.

Anggota KUBE di Kecamatan Sukamantri berjumlah 20 orang, diantaranya; Wati, Nuning, Laelasari, Nina, Iis, Niawati, Yoyoh, Yani, Eroh, Nia, Cucu, Aan, Rina, Rini, Nonoh, Afba, Siti, Wati, Ooy, Mira.

\section{Kelompok Usaha Bersama} (KUBE) di Kecamatan Sukamantri dibentuk pada bulan Agustus tahun 2016. Dalam pertemuan awal dibahas mengenai nama kelompok usaha, jenis usaha dan pembentukan struktur organisasi. Jenis usaha Kelompok Usaha Bersama (KUBE) di Kecamatan Sukamantri ini terdiri atas kelompok usaha warung.

Usaha warung merupakan usaha yang dipilih oleh kelompok KUBE Kecamatan Sukamantri karena dapat terbaca keuntungannya pada saat itu juga. Yang menjalankan usahanya yaitu ibuibu rumah tangga yang sebelumnya tidak memiliki penghasilan dan para suami mereka menjalankan pekerjaan lain seperti buruh tani. Jenis barang yang mereka jual seperti jajanan anak-anak, minuman, makanan dan sayuran bahkan ada warung yang menjual bensin.

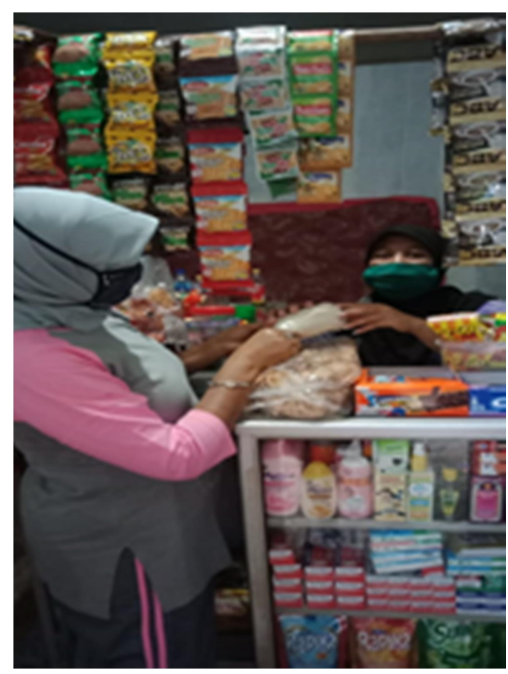

Gambar 1. Program KUBE Kecamatan Sukamantri (Kelompok warung)

\section{KUBE PKH di Kecamatan Panjalu}

Panjalu merupakan salah satu wilayah kecamatan yang ada di Kabupaten Ciamis. Kondisinya geografisnya merupakan daerah pegunungan. Disana terdapat situs yang dikeramatkan oleh masyarakat setempat sekaligus tempat wisata religi karena disana terdapat makam Borosngora. Aktifitas masyarakatnya ada yang bertani dan berdagang ada juga yang beternak. Baik itu berternak kambing, ayam, maupun bebek dan ikan. Namun memang tidak semua orang memiliki modal untuk 
berbisnis sebagai peternak. Banyak sebagian masyarakat yang menjadi buruh tani dan hidup dalam golongan prasejahtera. Hal yang membuat pemerintah setempat baik Desa maupun Kecamatan mangajukan bantuan dengan program Kelompok Usaha Bersama (KUBE).

Anggota Kelompok Usaha Bersama (KUBE) di Kecamatan Panjalu berjumlah 7 orang, diantaranya; Tuti, Siti Aminah, Yeti, Oom, Een Jubaedah, Haryati, Ii Ibut.

Kelompok Usaha Bersama (KUBE) di Kecamatan Panjalu yang memilik jenis usaha ayam petelor. Dalam menjalankan usaha ayam petelor awalnya kelompok ini kami tidak ada kendala. Namun lambat laun usaha ayam petelor tersebut ada sedikit kendala dengan adannya hama dan ada beberapa ayam yang mati. Namun setelah mereka berkonsultasi dengan pendamping KUBE di Kecamatan ada pencerahan mengenai perawatan ayam tersebut. Kelompok Usaha Bersama (KUBE) di Kecamatan Panjalu ini setiap satu bulan sekali rutin di adakan pertemuan di awal bulan. Pada pertemuan tersebut anggota sering membahas mengenai perkembangan usaha, pemasaran telur, cara perawatan ayam dan kandang ayamnya supaya tidak terkena hama atau sakit, jenis pakan yang baik untuk ayam petelur, pembersihan kandang ayam.

Ternak ayam petelur merupakan jenis usaha yang dipilih oleh kelompok Panjalu. Hal ini di dasarkan pada pendapatan yang akan diterima oleh peternak setiap hari. Mereka sudah menghitung per ekor dan kira-kira telur yang akan di dapatnya setiap hari serta pendistribusiannya.

Untuk pendistribusian mereka kirimkan ke warung-warung di sekitar Kecamatan Panjalu.

Untuk benih sendiri mereka mendapatkan harga yang lebih rendah dan untuk pakan juga sama. Meraka mendapatkan dari tempat yang sama yaitu dari daerah Cikijing. Selain itu untuk pembuatan kandang ayam mereka menyuruh tukang untuk membuatkan kandang ayam di atas kolam ikan milik warga setempat yang di tanami ikan lele. Dari hasil wawancara mereka menjelaskan bahwa dalam menernak ayam petelur ini memang susah gampang. Karena pakan juga harus diperhatikan, kebersihan kandang juga tidak boleh lepas kontrol serta ketersediaan air juga harus memadai. Tetapi positifnya dari menernak ayam petelur ini yaitu setiap harinya para ibu 
akan mendapatkan hasil dari penjualan telur tersebut.

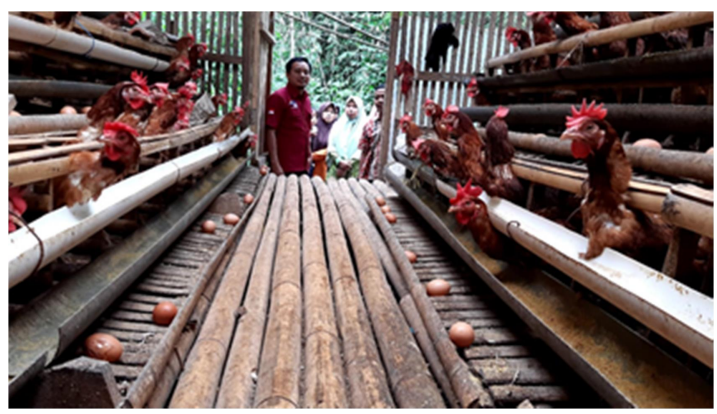

Gambar 2. Program KUBE Kecamatan Panjalu (Kelompok peternak ayam)

\section{KUBE PKH di Kecamatan Rajadesa}

Rajadesa adalah nama sebuah daerah tepatnya sebuah Kecamatan yang ada di Kabupaten Ciamis. Penduduk disana kebanyakan petani dan kaum buruh tani. Ada sebagian yang berdagang dan pegawai. Selain bertani juga mereka merupakan buruh pengrajin seperti pembuat boboko, hihid, tampir, Gebog, Sair, Aseupan dan lain-lain. Dari profesi mereka yang sebagian besar merupakan buruh tani dan pengrajin bambu, maka sudah di duga penghasilan mereka perbulannya kurang dari Rp. 500.000., Maka dari itu pemerintahan setempat mengadakan program KUBE yang sasarannya merupakan buruh tani dan buruh pengrajin.

Sama halnya seperti di Kecamatan Sukamantri dan Kecamatan Panjalu, di Kecamatan Rajadesa juga kami melakukan observasi sebanyak dua kali. Observasi pertama pada hari rabu tanggal 15 bulan April tahun 2020. Disana kami mewawancarai ibu Ijah dan anggota lainnya seperti ibu Eka, ibu Sofi, ibu Ajeng, ibu Eni, ibu Indah, ibu Endah, ibu Edah, ibu Yuli, ibu Siti, ibu Novi, ibu Dian.

Anggota Kelompok Usaha Bersama (KUBE) di Kecamatan Rajedesa berjumlah 12 orang, diantaranya; Ijah, Eka, Sofi, Ajeng, Eni, Indah, Endah, Edah, Yuli, Siti, Novi, Dian.

Kelompok Usaha Bersama (KUBE) di Kecamatan Rajadesa yang memilik jenis usaha ternak kambing. Dalam menjalankan usaha ternak kambing awalnya mereka tidak ada kendala. Namun lambat laun usaha ternak kambing tersebut ada sedikit kendala ketika memasuki musim kemarau. Peternak kesulitan mencari rumput untuk pakan kambing. Namun setelah berkonsultasi dengan pendamping KUBE di Kecamatan ada pencerahan mengenai perawatan kambing dan solusi ketika musim kemarau tiba. Kelompok Usaha Bersama (KUBE) di Kecamatan Rajadesa ini setiap satu bulan sekali rutin di adakan pertemuan di awal bulan. Pada pertemuan tersebut anggota sering membahas mengenai perkembangan usaha, 
pemasaran ternak, cara perawatan kambing dan kandangnya supaya tidak terkena hama atau sakit.

Ternak kambing merupakan jenis usaha yang dipilih oleh kelompok Rajadesa. Hal ini di dasarkan pada salah satu anggota yang sempat menernak kambing orang lain dengan sistim bagi hasil. Dan hasil yang di dapat cukup memuaskan. Tetapi memang untuk menernak kambing ini butuh kesabaran, karena butuh waktu lama untuk mendapatkan hasil yang memuaskan, setidaknya apabila datang bulan Idul Adha baru mereka kebanjiran pesanan. Kemudian kotoran kambingnyapun dapat dimanfaatkan sebagai pupuk dan bisa dijual dengan harga Rp.12.000-Rp. 15.000 untuk per karungnya. Penjalan usaha ini merupakan istri-istri dari petani yang beranggotakan 7 orang dibantu oleh para suami mereka.

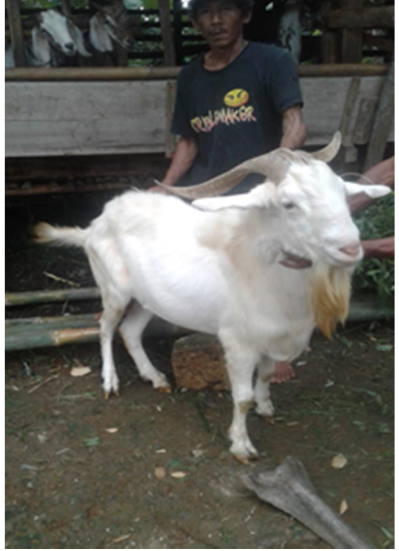

Gambar 3. Program KUBE Kecamatan Rajadesa (Kelompok peternak kambing) Evaluasi Program KUBE PKH

Evaluasi program KUBE PKH dilakukan dengan menggunakan 4 indikator, yaitu keteparan sasaran, sosialisasi program, tujuan program, dan pemantauan program.

\section{Ketepatan program}

Ketepatan program dianalisis dengan menggunakan 2 indikator, yaitu pendapatan sebelum mengikuti program, dan ketepatan penunjukan peserta program. Hasil analisis indikator ketepatan program disajikan pada Tabel 1.

Tabel 1. Ketepatan Sasaran KUBE PKH

\begin{tabular}{|c|c|c|c|c|c|c|c|c|}
\hline \multirow{3}{*}{ KUBE РКН } & \multicolumn{4}{|c|}{$\begin{array}{c}\text { Pendapatan }<\text { Rp } 500.000 \text { sebelum } \\
\text { mengikuti program }\end{array}$} & \multicolumn{4}{|c|}{ Ketepatan sasaran } \\
\hline & \multicolumn{2}{|c|}{ Ya } & \multicolumn{2}{|c|}{ Tidak } & \multicolumn{2}{|c|}{ Tepat } & \multicolumn{2}{|c|}{ Tidak Tepat } \\
\hline & Jml (org) & $\%$ & Jml (org) & $\%$ & Jml (org) & $\%$ & Jml (org) & $\%$ \\
\hline Sukamantri & 21 & 100,0 & 0 & 0,0 & 17 & 80,9 & 4 & 19,1 \\
\hline Panjalu & 5 & 71,4 & 2 & 28,6 & 7 & 100,0 & 0 & 0,0 \\
\hline Rajadesa & 5 & 71,4 & 2 & 28,6 & 7 & 100,0 & 0 & 0,0 \\
\hline
\end{tabular}

Tabel 1 menunjukkan bahwa penunjukan peserta program KUBE PKH telah tepat pada sasaran, yaitu penduduk yang berpendapatan kurang dari $\mathrm{Rp}$ 500.000. Ketepatan dalam penunjukan sasaran ini terkait dengan tujuan KUBE 
PKH yaitu meningkatkan pendapatan dari penduduk yang berkategori miskin.

\section{Sosialisasi program}

Sosialisasi program dianalisis dengan menggunakan 2 indikator, yaitu

Tabel 2. Sosialisasi Program KUBE PKH

\begin{tabular}{|c|c|c|c|c|c|c|c|c|}
\hline \multirow{3}{*}{ KUВE РКН } & \multicolumn{4}{|c|}{$\begin{array}{c}\text { Apakah ada sosialisasi program dari } \\
\text { dinas }\end{array}$} & \multicolumn{4}{|c|}{$\begin{array}{c}\text { Pendamping menyampaikan tujaun } \\
\text { program }\end{array}$} \\
\hline & \multicolumn{2}{|c|}{ Ya } & \multicolumn{2}{|c|}{ Tidak } & \multicolumn{2}{|c|}{ Tepat } & \multicolumn{2}{|c|}{ Tidak Tepat } \\
\hline & Jml (org) & $\%$ & Jml (org) & $\%$ & Jml (org) & $\%$ & Jml (org) & $\%$ \\
\hline Sukamantri & 15 & 71,4 & 6 & 28,6 & 20 & 95,2 & 1 & 4,8 \\
\hline Panjalu & 5 & 71,4 & 2 & 28,6 & 6 & 85,7 & 1 & 14,3 \\
\hline Rajadesa & 5 & 71,4 & 2 & 28,6 & 6 & 85,7 & 1 & 14,3 \\
\hline
\end{tabular}

Tabel 2 menunjukkan bahwa dinas melaksanakan sosialisasi program kepada penduduk yang menjadi peserta program. Selain itu, pendamping juga menjelaskan secara detil tujuan dari program. Hal ini dilakukan agar peserta memahami secara komprehensif mengenai program KUBE PKH, khususnya mengenai tujuan dari program tersebut. sosialisasi program yang disampaikan oleh dinas, dan penyampaian tujuan program oleh pendamping. Hasil analisis indikator sosialisasi program disajikan pada Tabel 2 .

\section{Tujuan program}

Tujuan program dianalisis dengan menggunakan 2 indikator, yaitu adanya peningkatan pendapatan dari peserta program setelah mengikuti program KUBE PKH, dan kesesuaian program dengan pelaksanaannya. Hasil analisis indikator tujuan program disajikan pada Tabel 3.

Tabel 3. Tujuan Program KUBE PKH

\begin{tabular}{lcccccccc}
\hline \multirow{2}{*}{ KUBE PKH } & \multicolumn{3}{c}{ Ada peningkatan pendapatan } & \multicolumn{3}{c}{ Pelaksanaan sesuai dengan tujuan } \\
\cline { 2 - 9 } & \multicolumn{2}{c}{ Ya } & \multicolumn{3}{c}{ Tidak } & \multicolumn{2}{c}{ Tepat } & \multicolumn{2}{c}{ Tidak Tepat } \\
\cline { 2 - 9 } & Jml (org) & \% & Jml (org) & \% & Jml (org) & \% & Jml (org) & \% \\
\hline Sukamantri & 18 & 85,7 & 3 & 14,3 & 21 & 100,0 & 0 & 0,00 \\
Panjalu & 7 & 100,0 & 0 & 0,0 & 7 & 100,0 & 0 & 0,0 \\
Rajadesa & 7 & 100,0 & 0 & 0,0 & 7 & 100,0 & 0 & 0,0 \\
\hline
\end{tabular}

Tabel 3 menunjukkan bahwa peserta mengalami peningkatan pendapatan setelah mengikuti program KUBE PKH, sehingga peserta menyatakan bahwa pelaksanaan program
KUBE PKH telah sesuai dengan pelaksanaannya. 


\section{Pemantauan program}

Pemantauan program dianalisis dengan menggunakan 2 indikator, yaitu apakah program telah dilaksanakan dengan baik, dan pemantauan dari dinas dan pendamping program. Hasil analisis indikator pemantauan program disajikan pada Tabel 4.

Tabel 4. Pemantauan Program KUBE PKH

\begin{tabular}{lcccccccc}
\hline & \multicolumn{3}{c}{ Program dilaksanakan dengan baik } & \multicolumn{2}{c}{ Pemantauan dari dinas dan pendamping } \\
\cline { 2 - 8 } KUBE PKH & \multicolumn{2}{c}{ Ya } & \multicolumn{2}{c}{ Tidak } & \multicolumn{2}{c}{ Tepat } & \multicolumn{2}{c}{ Tidak Tepat } \\
\cline { 2 - 9 } & Jml (org) & \% & Jml (org) & \% & Jml (org) & \% & Jml (org) & $\%$ \\
\hline Sukamantri & 19 & 90,5 & 2 & 9,5 & 21 & 100,0 & 0 & 0,0 \\
Panjalu & 7 & 100,0 & 0 & 0,0 & 7 & 100,0 & 0 & 0,0 \\
Rajadesa & 7 & 100,0 & 0 & 0,0 & 7 & 100,0 & 0 & 0,0 \\
\hline
\end{tabular}

Tabel 4 menunjukkan bahwa program KUBE PKH telah dilaksanakan dengan baik, ditunjang dengan adanya pemantauan program oleh dinas dan pendamping program. Pemantauan ini berguna agar program dapat terlaksana sesuai dengan tujuannnya.

\section{Kendala Pelaksanaan Program KUBE PKH}

Kendala yang ditemukan dalam pelaksanaan program KUBE PKH terkait dengan sumberdaya manusia peserta program, pendidikan dan ekonomi. Kendala-kendala tersebut diuraikan sebagai berikut:

\section{Pendidikan}

Sumber daya manusia adalah semua manusia yang terlibat di dalam suatu organisasi dalam mengupayakan terwujudnya tujuan organisasi tersebut (Hasibun, 2000). Untuk itu, manusia merupakan komponen penting dalam sebuah organisasi atau masyarakat sebagai penggerak untuk dapat mencapai tujuan dari visi dan misi. Keberhasilan suatu organisasi atau kelompok masyarakat dapat diwujudkan oleh kualitas manusianya itu sendiri dengan mewujudkan kompetensi yang mereka miliki.

Pendidikan terkait dengan proses mengolah, mengubah kejiwaan, mematangkan perasaan, pikiran, kemauan dan watak, mengubah kepribadian seseorang (Nurkholis, 2013). Hasil penelitian menunjukkan bahwa pendidikan peserta program KUBE PKH tergolong rendah, dengan komposisi pendidikan peserta adalah lulusan Sekolah Menengah Atas (SMA) 20\%, (SMP) 60\% dan (SD) 20\%. Rendahnya pendidikan ini terkait dengan kreativitas dan pola fikir peserta yang akan mempengaruhi perkembangan KUBEPKH. 
Terkait dengan rendahnya pendidikan peserta KUBE PKH tersebut, maka kegiatan pendampingan penting untuk dilaksanakan dengan argumentasi berikut:

a. Anggota KUBE sering kali kurang memahami secara benar bagaimana melakukan pekerjaan.

b. Perubahan dalam lingkungan terkait dengan adanya perubahan teknologi atau munculnya metode/cara kerja baru.

c. Meningkatkan daya saing dan memperbaiki produktivitas.

d. Menyesuaikan dengan peraturanperaturan yang ada, seperti standar pelaksanaan pekerjaan, kualitas produksi atau keselamatan dan kesehatan kerja.

Pendamping KUBE PKH bertugas: (a) membentuk KUBE, (b) memverifikasi calon penerima bantuan, (c) menyiapkan calon penerima bantuan, (d) menyiapkan rencana anggaran biaya, $€$ memberikan bimbingan teknis kepada KUBE, (f) memberikan bimbingan motivasi sosial, (g) medampingi pelaksanaan UEP yang dilaksanakan oleh KUBE, (h) memantau pelaksanaan kegiatan, dan (i) membantu dalam penyusunan laporan kegiatan.

\section{Ekonomi}

Ekonomi keluarga berarti urusan keuangan rumah tangga (organisasi, negara) yang didalamnya meliputi ibu, bapak dan anak dan merupakan satuan kekerabatan dalam masyarakat. Istilah ekonomi biasanya berhubungan dengan permasalahan kaya dan miskin, status sosial pada ekonomi keluarga ini pada setiap lingkungan masyarakat dengan sengaja atau tidak sengaja terbentuk dengan sendirinya (Soekanto, 1990).

Hasil penelitian menunjukkan bahwa $60 \%$ masyarakat di Kecamatan Panjalu, Kecamatan Sukamantri dan Kecamatan Rajadesa sebagian besar bekerja sebagai buruh tani. Kondisi ini menunjukkan rendahnya kemampuan ekonomi masyarakat, termasuk peserta program KUBE $\mathrm{PKH}$, yang berkaitan dengan rendahnya pendidikan dan sumberdaya peserta KUBE PKH.

\section{KESIMPULAN}

Pelaksanaan program KUBE-PKH di Kabupaten Ciamis telah sesuai dengan tujuan dari program tersebut, yaitu peningkatan kesejahteraan masyarakat. Hal ini ditunjukkan dengan indikator ketetapan sasaran, sosialisasi program, tujuan program, dan pemantauan program. 
Kendala-kendala yang ditemukan dalam pelaksanaan program KUBE-PKH di Kabupaten Ciamis terkait dengan faktor pendidikan dan ekonomi dari peserta program.

\section{DAFTAR PUSTAKA}

Singarimbun, M. (1989). Metode Penelitian Survai. Jakarta: LP3S.
Hasibuan, S. (2000). Manajemen Sumber Daya Manusia: Pendekatan Non Sekuler. Surakarta: Muhammadiyah University Press.

Nurkholis, Jurnal Kependidikan, Vol. 1 No. 1 Nopember 2013.

Soekanto, S. (1990). Sosiologi sesuatu pengantar, Jakarta: PT Raja grafindo Persada. 